\title{
Changes in soil microbial biomasses and their quotients over the succession of karst rocky desertification
}

\author{
XIE Lianwu, 1,2,a DENG Yanling ${ }^{1}$, WANG Bin², QIN Haijiao², Fang Jiqian², CAO \\ Fuxiang $^{3}$, WU Lichao ${ }^{1, b, *}$
}

${ }^{1}$ Central South University of Forestry \& Technology, i) Key Laboratory of Cultivation and Protection for Non-Wood Forest Trees, Ministry of Education; ii) Key Lab of Non-wood Forest Products of State Forestry Administration; iii) Cooperative Innovation Center of Cultivation and Utilization for Non-Wood Forest Trees of Hunan Province, Changsha 410004, China

${ }^{2}$ College of Sciences, Central South University of Forestry \& Technology, Changsha 410004, China

${ }^{3}$ College of Life Science and Technology, Central South University of Forestry \& Technology, Changsha 410004, China

axielianwu@csuft.edu.cn, bulichao@sina.com

* corresponding author

Keywords: karst rocky desertification; microbial biomass carbon (MBC); microbial biomass nitrogen (MBN); microbial biomass phosphorus (MBP); microbial biomass quotient

Abstract. To evaluate soil fertility of karst land undergoing rocky desertification (RD), the changing trend of soil microbial biomass properties over the succession of RD were studied by investigating the stands and analyzing the soil samples with four different RD grades in the northwestern Hunan province, China. The results showed that the changing trend of microbial biomass $\mathrm{C}$ (MBC), microbial biomass $\mathrm{N}(\mathrm{MBN})$, microbial biomass $\mathrm{P}(\mathrm{MBP})$, and the microbial biomass quotients including the ratio of $\mathrm{MBC}$ to total organic $\mathrm{C}$ (MBC/TOC), the ratio of $\mathrm{MBN}$ to total $\mathrm{N}$ (MBN/TN), and the ratio of MBP to TP (MBP/TP) was: potential RD > light $\mathrm{RD}>$ moderate RD > intensive RD, whereas the changing trend of microbial communities was not entirely consistent with the succession of RD. The increased grade of RD was significantly and negatively correlated to the increased contents of MBC $(r=-0.86), \operatorname{MBN}(r=-0.85)$, MBP $(r=-0.73), \operatorname{MBC} / T O C(r=-0.81)$, MBN/TN $(r=-0.64)$, and MBP/TP $(r=-0.72)$. The values of microbial biomass quotients were influenced by the content of organic matter inputting to soil. Therefore, microbial biomass $\mathrm{C}, \mathrm{N}, \mathrm{P}$ and microbial biomass quotients might be sensitive indicators to reflect the strength of soil fertility in the degraded karst regions.

\section{Introduction}

The karst mountain region of the northwestern Hunan province, being an evergreen broadleaved forest in the past time, now is one of the largest karst rocky desertification (RD) areas in southwestern China, which mainly caused by climate change and anthropogenic activities [1]. Karst rocky desertification, a process of land degradation involving serious soil erosion, extensive exposure of basement rocks, drastic decrease in soil productivity, and the appearance of a desert-like landscape [2], is recognized as an obstacle to local sustainable development. However, it was suggested that some $\mathrm{RD}$ regions could be meliorated by the comprehensively ecological reconstruction [3]. Thus, since 2001, comprehensive rehabilitation of karst RD areas in southwestern China had been put on the national agenda of the 'Tenth Five-year Plan'.

In the process of rehabilitation, understanding the soil fertility is fundamentally important to the reforestation. To our knowledge, soil physicochemical properties are usually taken into account to evaluate soil fertility, whereas microbial biomass properties are seldom involved in. However, microbial biomass are always relating to soil fertility, and microbiological activity directly influences soil ecosystem stability and fertility [4], because microbial turnover is a driving force for transformation and cycling of organic matter and plant nutrients in soils. In addition, the changes in 
microbial biomass $\mathrm{C}$ (MBC) can reflect the changes in the content of soil organic matter [5], so it is useful for evaluating natural and degraded systems [6]. Furthermore, the inorganic $\mathrm{N}$ and $\mathrm{P}$ needed by plants are mainly obtained from mineralized organic matter through microbial degradation. Therefore, the changes of $\mathrm{MBC}$, microbial biomass $\mathrm{N}(\mathrm{MBN})$, and microbial biomass $\mathrm{P}(\mathrm{MBP})$ can indicate the fluctuation of soil fertility [5], and a good level of microbiological activity is essential for maintaining soil quality. Thus, we could put forward that microbial biomass properties might be sensitive indicators to evaluate soil fertility in karst land during the succession of RD.

Succession of RD refers to the changing process of karst land from one grade to another here and elsewhere [7], which means an observable process of changes of karst ecosystem such as vegetation type, vegetation coverage, bedrock exposure, and soil depth from potential RD to intensive RD orderly or vice versa [8]. In karst ecosystem, in order to find sensitive indicators to evaluate soil fertility, many researches discussed the interactions among vegetation, soil physical and chemical conditions, and soil microbial properties. It was proved that $\mathrm{N}$ availability in karst area is regulated by soil organic matter, while microbial activity is restricted by soil $\mathrm{pH}[9,10]$. The vegetation restoration can improve soil microbial biomass $\mathrm{C}$, respiration, and utilization of carbon sources to create better soil conditions [11], which in turn could promote the restoration of vegetation on degraded karst regions. However, there is no evidence that the change of microbial biomass can indicate the status of karst RD. So we are eager to understand the effects of succession of RD on the soil microbial biomass. The objectives of this work were: i) to clarify the variation of 12 selected soil indicators including 9 microbial variables with the succession of RD, and ii) to identify whether the microbial biomass properties might be sensitive index to response the status of RD or not.

\section{Materials and methods}

Study area. The sampling sites are in karst region involving three counties, namely Longshan (LS), Cili (CL) and Shimen (SM) approximately ranging from $29^{\circ} 15^{\prime} \mathrm{N}$ to $30^{\circ} 20^{\prime} \mathrm{N}$ and from $109^{\circ} 10^{\prime} \mathrm{E}$ to $111^{\circ} 30^{\prime} \mathrm{E}$ in the northwestern Hunan province, China. Topographic features of this area include karst landforms and fluvial erosion landforms, characterized by hills, syncline valleys and mountains. The region is a sub-tropical warm-moist climate with mean annual air temperatures $17.5{ }^{\circ} \mathrm{C}$, and with mean annual precipitations of $1279 \mathrm{~mm}$ from 2000 to 2012, which were obtained from China Meteorological Data Sharing Service System online (http://cdc.cma.gov.cn/home.do).

Soil sampling and handling. We used a core cutter $(5 \mathrm{~cm}$ diameter) to take the soil samples before covering the holes carefully in the field. There were no endangered or protected species involved in this study. The permissions for sampling locations were approved by Forestry Bureau of LS, CL, and SM counties, respectively.

Table 1. Classification of rocky desertification and basic information of plots

\begin{tabular}{lllcccc}
\hline Grade & Vegetation & Utilization & Soil depth / cm & $\begin{array}{c}\text { Vegetation } \\
\text { coverage / \% }\end{array}$ & $\begin{array}{c}\text { Bedrock } \\
\text { exposure / \% }\end{array}$ & Serial No. of plots \\
\hline PRD & tree & forest conservation & $>40$ & $>70$ & $<30$ & CL1, LS1, SM1 \\
LRD & tree, shrub & timber stands, non-wood forests & $30-40$ & $50-70$ & $30-39$ & CL2, LS2, SM2 \\
MRD & shrub & non-wood forest, abandoned land & $20-29$ & $30-49$ & $40-49$ & CL3, LS3, SM3 \\
IRD & grass & abandoned land & $10-19$ & $20-29$ & $50-69$ & CL4, LS4, SM4 \\
\hline
\end{tabular}

SM, LS, and CL are the sampling plots standing for Shimen, Longshan, and Cili counties at northwest Hunan province, China, respectively. PRD, LRD, MRD, and IRD refer to potential, light, moderate, and intensive rocky desertification, respectively. A given RD grade should simultaneously satisfy the pre-established ranges for two out of three variables (soil depth, vegetation coverage and bedrock exposure).

RD regions are divided into 4 grades, namely potential RD (PRD), light RD (LRD), moderate RD (MRD), and intensive RD (IRD) based on the soil depth, vegetation coverage, bedrock exposure and vegetation type, which described in the Monitoring Rules of Rocky Desertification in Hunan Province issued in 2011 by Hunan Provincial Bureau of Forestry. Twelve plots ( 3 plots each RD grade) were chosen as the sampling sites (Table 1). The plots, designated LS1 - LS4, CL1 - CL4, SM1 - SM4, 
were all approximately $400 \mathrm{~m}^{2}$ in area. Totally 72 soil samples (6 samples per plot) were collected in these fields from 16 to 22 October 2011. At each sampling plot, six points were evenly distributed by walking in " $S$ " shape way over the area. And at each point, three cores $(5 \mathrm{~cm}$ diameter, $0-20 \mathrm{~cm}$ depth) were taken from three vertices of one triangle patch $(0.5 \mathrm{~m}$ side length). After plant debris, roots and stones were removed, these three cores were mixed thoroughly in a clean pail without sieving to give one composite sample. Every composite sample was divided into two parts, a field-moist sample and an air-dried one. The field-moist samples were kept in refrigerator under $-20{ }^{\circ} \mathrm{C}$ until culturing microbe to count bacteria (BAC), fungi (FUN), and actinomycetes (ACT), and analyzing MBC, MBN and MBP. The air-dried samples were used to determinate total organic carbon (TOC), total nitrogen (TN) and total phosphorus (TP).

Soil physicochemical properties analyses. Vegetation coverage was measured on site using digital camera method after calculating the ratio of red to near-infrared brightness of image recorded and processed $[12,13]$. Based on calculating the ratio of bedrock area to whole image, bedrock exposure was estimated using dimension measurements on site using a Nikon DTM322 total station surveying instrument (Nikon-Trimble Co. Ltd., Japan). TOC content was measured by dichromate oxidation method [14]. TN and TP contents were measured on a Smartchem ${ }^{\mathrm{TM}} 200$ discrete automatic analyzer (AMS, Italy) after digestion [15] and after fusion-pretreated with sodium hydroxide respectively.

Soil microbial biomass properties analyses. Measurements of MBC, MBN, and MBP were tested by chloroform-fumigation method described elsewhere [16, 17]. The density of soil microorganisms including BAC, FUN, and ACT were measured by dilution plating method [18].

Statistical analyses. All statistical analyses were performed using SPSS Statistics (ver. 20, IBM, USA). Differences in soil fertility indicators among different RD grades were analyzed using one-way analysis of variance (ANOVA). If there was significant difference, post hoc tests (Bonferroni correction) were used. Assumptions of ANOVA were checked. If equal variance could not be assumed between 4 RD grades, a further Brown-Forsythe test was done instead of ANOVA.

\section{Results}

Variation of soil microbial biomass properties with succession of RD. The results showed that the succession of RD affected 9 selected soil microbial indicators and 3 chemical indicators to different extent (Table 2). The content of TOC, TN, MBC, MBN, MBP, MBC/TOC, MBN/TN, and MBP/TP decreased with the aggravation of RD ( $\mathrm{p}<0.05$ ). The content of MBC, MBN, and MBP changed sharply ranging from 49.83 to $203.03 \mathrm{mg} \cdot \mathrm{kg}^{-1}$, from 27.57 to $140.20 \mathrm{mg} \cdot \mathrm{kg}^{-1}$, from 2.08 to 14.57 $\mathrm{mg} \cdot \mathrm{kg}^{-1}$, respectively. TOC, TN, MBC, MBN, MBC/TOC, and MBN/TN values of PRD were significantly bigger than those of LRD, MRD, or IRD, while the difference between those values of LRD and MRD was not significant. There were significant difference between TP, MBP, and MBP/TP of PRD with those of IRD. The changing trend of TP and BAC was: PRD > MRD > LRD > IRD. The content of FUN and ACT were not significantly different from succession of RD. 
Table 2. Effects of succession of rocky desertification on soil fertility indicators*

\begin{tabular}{lllll}
\hline Test items & PRD & LRD & MRD & IRD \\
\hline TOC $\left(\mathrm{g} \cdot \mathrm{kg}^{-1}\right)$ & $38.23 \pm 12.67 \mathrm{a}$ & $24.37 \pm 3.00 \mathrm{~b}$ & $20.37 \pm 1.05 \mathrm{~b}$ & $17.27 \pm 5.15 \mathrm{c}$ \\
$\mathrm{TN}\left(\mathrm{g} \cdot \mathrm{kg}^{-1}\right)$ & $3.85 \pm 2.68 \mathrm{a}$ & $1.92 \pm 0.37 \mathrm{~b}$ & $1.75 \pm 0.21 \mathrm{~b}$ & $1.65 \pm 0.30 \mathrm{c}$ \\
$\mathrm{TP}\left(\mathrm{g} \cdot \mathrm{kg}^{-1}\right)$ & $0.77 \pm 0.73 \mathrm{a}$ & $0.58 \pm 0.13 \mathrm{ab}$ & $0.25 \pm 0.04 \mathrm{ab}$ & $0.38 \pm 0.17 \mathrm{~b}$ \\
$\mathrm{MBC}\left(\mathrm{mg} \cdot \mathrm{kg}^{-1}\right)$ & $203.03 \pm 69.07 \mathrm{a}$ & $121.30 \pm 28.09 \mathrm{~b}$ & $67.43 \pm 47.48 \mathrm{~b}$ & $49.83 \pm 21.42 \mathrm{c}$ \\
$\mathrm{MBN}\left(\mathrm{mg} \cdot \mathrm{kg}^{-1}\right)$ & $140.20 \pm 58.40 \mathrm{a}$ & $97.30 \pm 32.55 \mathrm{~b}$ & $36.97 \pm 47.47 \mathrm{~b}$ & $27.57 \pm 12.40 \mathrm{c}$ \\
MBP $\left(\mathrm{mg} \cdot \mathrm{kg}^{-1}\right)$ & $14.57 \pm 9.31 \mathrm{a}$ & $6.59 \pm 1.50 \mathrm{a}$ & $2.24 \pm 0.67 \mathrm{~b}$ & $2.08 \pm 0.88 \mathrm{a}$ \\
$\mathrm{MBC} / \mathrm{TOC}(\%)$ & $0.63 \pm 0.09 \mathrm{a}$ & $0.50 \pm 0.12 \mathrm{~b}$ & $0.37 \pm 0.15 \mathrm{~b}$ & $0.24 \pm 0.11 \mathrm{c}$ \\
$\mathrm{MBN} / \mathrm{TN}(\%)$ & $5.50 \pm 3.03 \mathrm{a}$ & $4.37 \pm 1.77 \mathrm{~b}$ & $1.97 \pm 1.30 \mathrm{c}$ & $1.63 \pm 0.86 \mathrm{c}$ \\
$\mathrm{MBP} / \mathrm{TP}(\%)$ & $2.38 \pm 1.38 \mathrm{a}$ & $1.14 \pm 0.09 \mathrm{a}$ & $0.94 \pm 0.40 \mathrm{a}$ & $0.67 \pm 0.42 \mathrm{~b}$ \\
BAC $\left(\times 10^{3} \mathrm{CFU} \cdot \mathrm{g}^{-1}\right)$ & $2.62 \pm 2.65 \mathrm{a}$ & $1.23 \pm 1.26 \mathrm{~b}$ & $1.90 \pm 1.34 \mathrm{a}$ & $0.23 \pm 0.17 \mathrm{c}$ \\
FUN $\left(\times 10^{3} \mathrm{CFU} \cdot \mathrm{g}^{-1}\right)$ & $2.29 \pm 0.91 \mathrm{a}$ & $2.89 \pm 1.88 \mathrm{a}$ & $3.70 \pm 1.31 \mathrm{~b}$ & $1.52 \pm 1.36 \mathrm{a}$ \\
ACT $\left(\times 10^{3} \mathrm{CFU} \cdot \mathrm{g}^{-1}\right)$ & $2.57 \pm 0.71 \mathrm{a}$ & $0.93 \pm 0.31 \mathrm{~b}$ & $1.32 \pm 1.24 \mathrm{a}$ & $1.62 \pm 0.55 \mathrm{a}$ \\
\hline
\end{tabular}

* TOC, Total organic carbon; TN, total nitrogen; TP, total phosphorus; MBC, microbial biomass carbon; MBN, microbial biomass nitrogen; MBP, microbial mass phosphorous; BAC, bacteria; FUN, fungi; ACT, actinomycetes. PRD, LRD, MRD, and IRD refer to potential, light, moderate, and intensive rocky desertification, respectively. Means $\pm \mathrm{SD}(\mathrm{n}=3)$ within each row, for each indicator, followed by the same letter are not significantly different in ANOVA post hoc test at $p \leq 0.05$ after Bonferroni correction done.

Correlation of microbial biomass properties with the rocky desertification grade. In order to calculate the correlation coefficient between soil microbial biomass and the rocky desertification grade, a value was assigned to each desertification grade, i.e., 1 to PRD, 2 to LRD, 3 to MRD, and 4 to IRD. The TOC, TN, TP, MBC, MBN, MBC/TOC, MBN/TN, and MBP/TP were significantly and negatively correlated with the rocky desertification grade, in which the correlation coefficient between MBC and desertification grade reached the highest absolute value $(r=-0.86, p<0.01)$. The correlation coefficients between MBC/TOC $(r=-0.81, p<0.01)$, MBN/TN $(r=-0.64, p<0.01)$ or $\mathrm{MBP} / \mathrm{TP}(\mathrm{r}=-0.72, \mathrm{p}<0.05)$ and the rocky desertification grade were not remarkably different from those of MBC, MBN or MBP, but were more significant than those of TOC, TN or TP. Meanwhile, TOC, TN, TP, MBC, MBN, MBP, MBC/TOC, MBN/TN, MBP/TP, BAC and ACT were positively correlated with TOC, while FUN was not significantly correlated with all selected parameters.

Effect of TOC on microbial community. The effect of TOC on microbial community was showing in Fig. 1. The site with higher content of TOC led to a larger abundance of microbial community, and the fungi took up the largest percentage of microorganism in almost every site.

Fig. 1. Microbial community changing with the total organic $\mathrm{C}$ of sampling sites

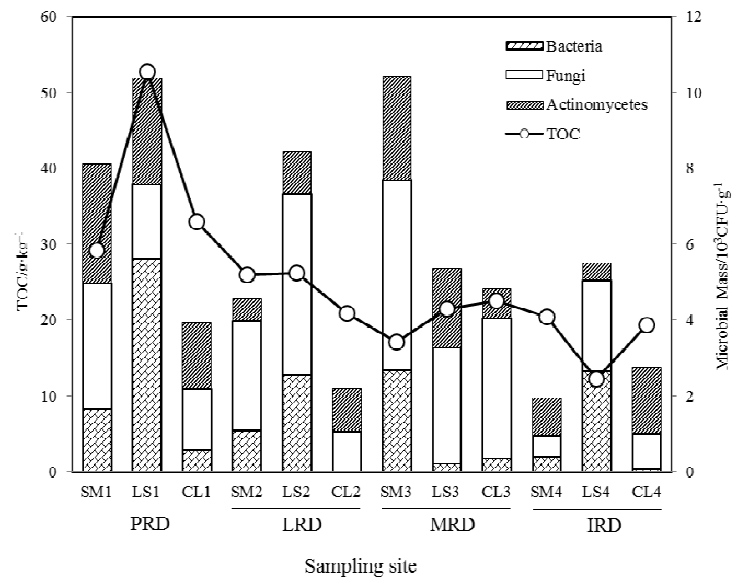




\section{Discussions}

Effects of succession of RD on soil microbial biomass properties. The aggravation of RD caused the soil microbial activity to decrease sharply (Table 1). The aggravation of RD is not only caused by anthropogenic factor (land overuse), but also by climate change [19]. For all investigated stands, we found that degradation of phytocommunity (tree $\rightarrow$ tree/shrub $\rightarrow$ shrub $\rightarrow$ shrub/grass $\rightarrow$ grass) results in the homogenization of community structure, decrease of biomass and litter fall, and reduction of plant nutrition [8]. The destroyed soil ecosystem leads to soil microorganism population reducing and microbial activity on discomposing litter fall decreasing, so that the $\mathrm{C}, \mathrm{N}$, and $\mathrm{P}$ fixation of soil decreases [20]. Then this led to soil hardening, bulk density enlarging, water/air permeability worsening, and water storage capacity of surface soil decreasing, thus the strong surface runoff causes great loss of $\mathrm{N}, \mathrm{P}$, and $\mathrm{K}$ nutrients in soil [8]. In one word, multiple affects above eventually led to microbial activity decreasing with the succession of rocky desertification.

Relationship between the grade of RD and microbial indicators. In this study, we found that the soil microbial biomasses (including $\mathrm{MBC}, \mathrm{MBN}$ and $\mathrm{MBP}$ ) and microbial biomass quotients (MBC/TOC, MBN/TN, and MBP/TP) were correlated negatively with rocky desertification grade (Table 2). The populations of BAC, FUN and ACT were correlated negatively but insignificantly with rocky desertification grade. As to the correlations of MBC with TOC, MBN with TN, and MBP with $\mathrm{TP}$, our results were similar to those reported findings [21, 22]. Soil organic matter content is an important factor that directly restricts microbial growth, thus soil microbial biomass $\mathrm{C}$ declines while total soil organic $\mathrm{C}$ concentrations decrease significantly. Microbial biomass $\mathrm{P}$ was positively correlated with soil organic $\mathrm{C}$ and total $\mathrm{P}$, reflecting the importance of soil organic matter as a $\mathrm{P}$ source [21].

On the basis of considering microbial biomass $\mathrm{C}, \mathrm{N}$ and $\mathrm{P}$, the larger ratios of $\mathrm{MBC} / \mathrm{TOC}$, $\mathrm{MBN} / \mathrm{TN}$ and MBP/TP means more percentage of organic matter could be mineralized and plants could ingest more percentage of inorganic nutrition. Changes in the MBC/TOC ratio reflect the input of organic matter to soils, the efficiency of microbial incorporation, $\mathrm{C}$ losses from the soils, and the stabilization of organic $\mathrm{C}$ by the soil mineral fractions [23]. So we could presumably believe that plant-availability of $\mathrm{N}$ and $\mathrm{P}$ in soils mainly depends on biological cycling when the fertilizer are unavailable. So the ratios of MBC/TOC, MBN/TN and MBP/TP could be sensitive parameters to monitor organic matter dynamics and available fertilizer to plants.

Factors controlling microbial biomass quotients. Although many factors (vegetation coverage, land use type, elevation, slope, aspect, lithology and settlement buffer) drive rocky desertification, land use is a key driving factor of rocky desertification [24] because it represents excessive human activities on land. Thus, reducing human activities and taking measurements such as mountain closure, forest reservation and plantation might be definitely important to control the expanding of rocky desertification area. Similarly, these factors also act on microbial biomass quotients. In our study, after evaluating the absolute value of correlations coefficients between the microbial biomass quotients and the tested parameters, we found that the important factors controlling microbial biomass quotients were TOC, MBC, MBN, and MBP, BAC, FUN, and ACT. All of these indices might be affected by the input of organic matter to soil. The effect of TOC on microbial structure community was showing in Fig. 1. The results indicated that soil organic carbon content was the most important factor that directly restricted microbial growth, which affected microbial biomass quotients in the end.

\section{Conclusions}

In conclusion, aggravation of RD caused the soil microbial activity to decrease. The increased rocky desertification grade was negatively correlated to the increased contents of microbial biomass $\mathrm{C}$, microbial biomass $\mathrm{N}$, microbial biomass $\mathrm{P}$, the ratio of microbial biomass $\mathrm{C}$ to total organic $\mathrm{C}$ (MBC/TOC), the ratio of microbial biomass $\mathrm{N}$ to total $\mathrm{N}$ (MBN/TN) and the ratio of microbial biomass $\mathrm{P}$ to total $\mathrm{P}$ (MBP/TP). On the basis of considering quantities of microbial biomass, the ratios 
of $\mathrm{MBC} / \mathrm{TOC}, \mathrm{MBN} / \mathrm{TN}$ and MBP/TP might be the most important indexes among microbial biomass properties to response the status of rocky desertification. A classified rule of corresponding relation between these two sets could be established if more extensive investigations had been accomplished.

\section{Acknowledgments}

This research was supported by National Department Public Benefit Research Foundation of State Forestry Administration of China (201104016) and the Planned Science and Technology Project of Hunan Province, China (2013RS4035), and was partially funded by China Postdoctoral Science Foundation funded project (2013M531787) and the Technology Foundation for Selected Overseas Chinese Scholar, Ministry of Human Resources and Social Security of China. We are grateful to the Forestry Bureau of Shimen, Longshan, and Cili counties of Hunan for providing the sampling sites. We also acknowledge the anonymous reviewers for the valuable comments.

\section{References}

[1] Q.H. Huang, Y.L. Cai, X.S. Xing, Rocky desertification, antidesertification, and sustainable development in the karst mountain region of Southwest China. Ambio. 37 (2008) 390-392.

[2] S.J. Wang, Q.M. Liu, D.F. Zhang, Karst rocky desertification in southwestern China: Geomorphology, landuse, impact and rehabilitation. Land Degradation \& Development. 15 (2004) 115-121.

[3] Q.H. Huang, Y.L. Cai, Spatial pattern of karst rock desertification in the middle of Guizhou province, southwestern China. Environmental Geology. 52 (2007) 1325-1330.

[4] J.A. Pascual, C. García, T. Hernandez, et al., Changes in the microbial activity of an arid soil amended with urban organic wastes. Biology and Fertility of Soils. 24 (1997) 429-434.

[5] D.S. Powlson, P.C. Prookes, B.T. Christensen, Measurement of soil microbial biomass provides an early indication of changes in total soil organic matter due to straw incorporation. Soil Biology and Biochemistry. 19 (1987) 159-164.

[6] G. Soulas, R. Chaussod, A. Verguet, Chloroform fumigation technique as a means of determining the size of specialized soil microbial populations: Application to pesticide-degrading microorganisms. Soil Biology and Biochemistry. 16 (1984) 497-501.

[7] L. Xie, S. Wang, Variations of nutrient element contents of plants and soils in the process of karst rocky desertification. Chinese Journal of Geochemistry. 25 (2006) 176-176.

[8] L.W. Xie, J. Zhong, F.F. Chen, et al., Evaluation of soil fertility in the succession of karst rocky desertification using principal component analysis. Solid Earth. 6 (2015) 515-524.

[9] Y. Tian, K. Takanashi, H. Toda, et al., $\mathrm{pH}$ and substrate regulation of nitrogen and carbon dynamics in forest soils in a karst region of the upper Yangtze River basin, China. Journal of Forest Research. 18 (2013) 228-237.

[10] Y. Tian, K. Haibara, H. Toda, et al., Microbial biomass and activity along a natural $\mathrm{pH}$ gradient in forest soils in a karst region of the upper Yangtze River, China. Journal of Forest Research. 13 (2008) 205-214.

[11] S. Claassens, K.J. Riedel, L. Van Rensburg, et al., Soil microbial properties in coal mine tailings under rehabilitation. Applied Ecology and Environmental Research. 4 (2006) 75-83.

[12] M.A. White, G.P. Asner, R.R. Nemani, et al., Measuring fractional cover and leaf area index in arid ecosystems: digital camera, radiation transmittance, and laser altimetry methods. Remote Sensing of Environment. 74 (2000) 45-57.

[13] K.A. Warren-Rhodes, K.L. Rhodes, L.N. Boyle, et al., Cyanobacterial ecology across environmental gradients and spatial scales in China's hot and cold deserts. Fems Microbiology Ecology. 61 (2007) 470-482.

[14] J.C. Yeomans, J.M. Bremner, A rapid and precise method for routine determination of organic carbon in soil. Communications in Soil Science and Plant Analysis. 19 (1988) 1467-1476.

[15] P.C. Brookes, J.F. Kragt, D.S. Powlson, et al., Chloroform fumigation and the release of soil nitrogen: The effects of fumigation time and temperature. Soil Biology and Biochemistry. 17 (1985) 831-835.

[16] J. Wu, R.G. Joergensen, B. Pommerening, et al., Measurement of soil microbial biomass C by fumigation-extraction-an automated procedure. Soil Biology \& Biochemistry. 22 (1990) 1167-1169. 
[17] P.C. Brookes, A. Landman, G. Pruden, et al., Chloroform fumigation and the release of soil nitrogen: A rapid direct extraction method to measure microbial biomass nitrogen in soil. Soil Biology \& Biochemistry. 17 (1985) 837-842.

[18] L.R. Bulluck Iii, M. Brosius, G.K. Evanylo, et al., Organic and synthetic fertility amendments influence soil microbial, physical and chemical properties on organic and conventional farms. Applied Soil Ecology. 19 (2002) 147-160.

[19] S. Li, X. Wei, J. Huang, et al., The causes and processes responsible for rocky desertification in karst areas of southern China. Sciences in Cold and Arid Regions. 1 (2009) 80-90.

[20] N.C. Banning, D.B. Gleeson, A.H. Grigg, et al., Soil microbial community successional patterns during forest ecosystem restoration. Applied and Environmental Microbiology. 77 (2011) 6158-6164.

[21] R.G. Joergensen, H. Kubler, B. Meyer, et al., Microbial biomass phosphorus in soils of beech (Fagus sylvatica L.) forests. Biology and Fertility of Soils. 19 (1995) 215-219.

[22] L.P. Qiu, X.R. Wei, X.C. Zhang, et al., Soil organic carbon losses due to land use change in a semiarid grassland. Plant and Soil. 355 (2012) 299-309.

[23] G. Sparling, Ratio of microbial biomass carbon to soil organic carbon as a sensitive indicator of changes in soil organic matter. Soil Research. 30 (1992) 195-207.

[24] P.P. Zhang, Y.M. Hu, D.N. Xiao, et al., Rocky desertification risk zone delineation in karst plateau area: a case study in Puding county, Guizhou province. Chinese Geographical Science. 20 (2010) 84-90. 